\title{
PENYUSUNAN LAPORAN KEUANGAN ORGANISASI NIRLABA BERDASARKAN PERNYATAAN STANDAR AKUNTANSI KEUANGAN (PSAK) NOMOR 45 (Studi Pada Masjid Al-Iman Bukit Tinggi)
}

\author{
Reza Muhammad Rizqi, M.Ak ${ }^{1}$, Nurfadliyah, M.S.A ${ }^{2}$ \\ ${ }^{1}$ Program Studi Manajemen Universitas Teknologi Sumbawa \\ ${ }^{2}$ Program Studi Akuntansi Universitas Teknologi Sumbawa \\ Fakultas Ekonomi dan Bisnis Universitas Teknologi sumbawa
}

*Corresponding Author email: Email: reza.muhammad.rizqi@uts.ac.id

\begin{tabular}{ll}
\hline & ABSTRAK \\
& Penelitian ini bertujuan untuk menyusun laporan keuangaan Masjid Samsul Hidayah \\
& Desa Moyo sesuai dengan standar yang di buat oleh Ikatan Akuntan Indonesia (IAI) \\
Diterima: & yaitu Pernyataan Standar Akuntansi Keuangan (PSAK) No 45. Dalam penelitian \\
Bulan Juni 2020 & $\begin{array}{l}\text { ini, penulis melakukan analisis data laporan keuangan Masjid Samsul Hidayah } \\
\text { dengan cara mengumpulkan data, menyajikan data, menganalisa data, sehingga }\end{array}$ \\
Diterbitkan: & menghasilkan kesimpulan tentang gambaran yang sebenarnya, kemudian \\
Bulan Juli 2020 & membandingkan dengan Pernyataan Standar Akuntansi Keuangan (PSAK) No.45. \\
& jenis penelitian ini adalah kualitatif dengan pendeketan interpretif. Penulis \\
KataKunci: & menggunakan teknik pengumpulan data melalui observasi, wawancara, dan \\
Pernyataan & dokumentasi untuk mendapatkan data yang relevan. Hasil penelitian ini \\
Standar & menunjukkan bahwa laporan keuangaan Masjid Al-Iman Bukit Tinggi hanya berupa \\
Akuntansi & laporan pencatatan penerimaan kas dan pengeluaran kas serta saldo akhir masjid \\
Keuangan & dengan sederhana. Namun, pengurus masjid kurang menginventarisasikan jumlah \\
Nomor45, & aset yang dimiliki masjid. Laporan keuangan Masjid Al-Iman Bukit Tinggi tidak \\
laporan keuangan & sesuai dengan Pernyataan Standar Akuntansi Keuangan (PSAK) No.45 yang terdiri \\
organisasi & dari Laporan Posisi Keuangan, Laporan Aktivitas, Laporan Arus Kas, dan Catatan \\
nirlaba. & Atas Laporan Keuangan. \\
\hline
\end{tabular}

\section{PENDAHULUAN}

\section{A. Latar Belakang}

Organisasi merupakan hal yang sangat penting dalam kehidupan masyarakat. Organisasi adanya didirikan karena kesamaan kepentingan, baik dalam rangka untuk mewujudkan hakikat kemanusiaan maupun secara berkelanjutan untuk memenuhi kebutuhan.

Organisasi yang berorientasi atau memiliki tujuan yang bersifat laba maupun non laba selalu berusaha untuk mencapai tujuannya. Organisasi pada dasarnya digunakan sebagai tempat atau wadah dimana orang orang berkumpul dan bekerja sama secara rasional dan sistematik untuk mencapai tujuan yang telah dibuat atau ditetapkan. Menurut Yunus dan Nawawi (2013: 3) organisasi merupakan

sekelompok manusia yang bekerja sama dalam melakukan kegiatan yang dibimbing oleh seorang pemimpin dalam upaya mencapai tujuannya.

Organisasi nirlaba atau organisasi nonprofit merupakan salah satu komponen organisasi dalam masyarakat yang peranannya sangat penting. Tanpa disadari dalam kehidupan seharihari semakin banyak keterlibatan lembagalembaga nirlaba contohnya yayasan, pendidikan, organisasi jasa sukarelawan, organisasi keagamaan, dan masih banyak lagi. Menurut Mardiasmo (2015) organisasi nirlaba merupakan organisasi yang tidak mencari laba seperti organisasi keagamaan, yayasan atau lembaga pendidikan. Sedangkan menurut 
Pernyataan Standar Akuntansi Keuangan (PSAK No. 45), bahwa organisasi nirlaba memperoleh sumber daya dari para anggota dan para penyumbang lain yang tidak mengharapkan imbalan apapun dari organisasi tersebut (IAI, 2011:45.1). Walaupun organisasi ini tidak mencari keuntungan, namun mereka tetap bergelut dalam urusan keuangan, karena mereka mempunyai anggaran seperti, tenaga kerja, listrik dan air, serta urusan keuangan lainnya.

Karakteristik organisasi nirlaba ini berbeda dengan organisasi bisnis. Perbedaan yang paling mendasar terletak pada cara organisasi ini mendapatkan sumber dana yang dibutuhkan untuk melakukan berbagai aktivitas operasinya. Organisasi nirlaba memperoleh sumber daya dari sumbangan para penyumbang yang tidak mengharapkan pembayaran kembali atau pengembalian manfaaat ekonomi yang sebanding dengan jumlah sumber daya yang diberikan (Ikatan Akuntan Indonesia, 2012). Dalam PSAK No. 45, karakteristik organisasi nirlaba ditandai dengan perolehan sumbangan untuk sumber daya utama (aset), penyumbang bukan pemilik organisasi dan tidak berharap akan hasil, imbalan, serta keuntungan komersial. Karakteristik khusus ini menimbulkan jenis transaksi, siklus operasi, pola pengelolaan keuangan, perlakuan akuntan dan kebutuhan pelaporan keuangan yang berbeda dengan organisasi bisnis pada umumnya. Masjid merupakan salah satu organisasi nirlaba dalam bidang keagamaan, sesuai dengan Pernyataan Standar Akuntansi Keuangan (PSAK) No. 45 tahun 2011 tentang organisasi nirlaba, bahwa organisasi nirlaba harus dan berhak untuk membuat laporan keuangan dan melaporkan kepada para pemakai laporan keuangan. Masjid harus membuat laporan keuangan yang akurat dan memberikan informasinya kepada pengguna laporan keuangan tersebut yaitu para donatur masjid. Untuk dapat membuat laporan keuangan dana masjid dengan akurat dibutuhkan penerapan akuntansi, dan peranan akuntansi untuk memperlancar manajemen keuangan dalam fungsinya sebagai alat perencanaan, pengawasan dan pengambilan keputusan. Pencatatan keuangan masjid biasanya hanya mencakup penerimaan dan pengeluaran kas serta saldo akhir masjid saja tanpa melihat jumlah aset yang dimiliki dan berapa nilainya, sehingga banyak kasus hilangnya aset masjid karena lemahnya sistem pencatatan laporan keuangan. Dengan demikian, organisasi keagamaan masjid adalah organisasi nirlaba yang sesuai dengan PSAK No. 45 tahun 2011 tentang operasi nirlaba, maka organisasi keagamaan masjid harus membuat laporan keuangan serta melaporkan kepada pemakai laporan keuangan, yaitu donator atau masyarakat, sebabagai pertanggungjawaban pengurus organisasi (masjid) terhadap dana yang telah diterima. Belum lagi jika antara masjid yang satu dengan yang lainnya terdapat perbedaan yang sangat mencolok, masjid yang satu memiliki dana yang cukup besar sedangkan yang lainnya sangat minim. Sehingga pengurus masjid harus berusaha keras mencari sumbangan dan hal ini menjadi citra buruk bagi pemeluk agama lain bahwa umat musllim identik dengan minta-minta. Maka dengan penerapan sistem keuangan yang baik akan memberikan jawaban yang tepat atas ketidakpercayaan masyarakat terhadap organisasi masjid dan takmir/pengurusnya.

Tujuan dibuatnya laporan keuangan pada organisasi nirlaba agar terciptanya laporan keuangan yang mudah untuk dipahami, relevan, dan memiliki daya banding yang tinggi. Oleh karena itu, pembuatan laporan keuangan organisasi masjid sangat penting untuk melihat bagaimana pengelolaan keuangan yang telah dilaksankan dan sebagai pertanggungjawaban pengerus masjid. Dengan adanya pertanggungjawaban yang baik akan meningkatkan kepercayaan masyarakat atau donatur terhadap organisasi masjid. Karena pentingnya laporan keuangan bagi entitas nirlaba, maka Ikatan Akuntan Indonesia (IAI) menerbitkan Pernyataan Standar Akuntansi Indonesia (PSAK) No. 45 mengenai pelaporan keuangan organisasi nirlaba. Ikatan Akuntan Indonesia (IAI) selaku otoritas yang berwewenang menyusun standar akuntansi di Indonesia menetapkan standar khusus bagi organisasi nirlaba dalam Pernyataan Standar Akuntansi Keuangan (PSAK) No. 45 (Revisi 2011) sehingga suatu entitas nirlaba dalam menyusun laporan keuangan mengacu pada standar yang berlaku yaitu PSAK No. 45. Dengan adanya standar tersebut diharapkan semua organisasi nirlaba yang ada di Indonesia dapat menerapkannya, mengingat pelaporan keuangan organisasi nirlaba berbeda dengan organisasi bisnis. Beberapa penelitian terdahulu yang pernah dilakukan, salah satunya oleh Ervianti Jianti (2017) dalam penelitiannya 
menyatakan bahwa dalam akuntansi pokok yang diterapkan pada masjid Al-Jihad di Banjarmasin masih belum terbangun dengan baik. Laporan keuangan yang dihasilkan hanya berupa laporan keuangan bulanan yang sederhana, dimana dalam laporan keuangan tersebut hanya terdapat penerimaan dan pengeluaran kas serta saldo akhir, sehingga belum menghasilkan laporan keuangan yang transparan. Melihat masalah yang terjadi pada penelitia-penelitian sejenis, begitu pula pada organisasi masjid. Salah satunya yang terjadi pada Masjid Samsul Hidayah Desa Moyo. Dimana berdasarkan observasi awal yang dilakukan peneliti dengan pengurus Masjid Samsul Hidaya Desa Moyo, diketahui bahwa Masjid Samsul Hidayah Desa Moyo terdapat permasalahan dalam laporan keuangan masjid. Dimana Masjid Samsul Hidaya hanya melakukan pencatatan penerimaan kas dan pengeluaran kas serta saldo akhir masjid dengan sederhana. Namun, pengurus masjid kurang menginventarisasikan jumlah aset yang dimiliki masjid. Masjid Samsul Hidayah desa Moyo berlokasi di RT 1, RW 1, Dusun Moyo Luar, Desa Moyo, Kecamatan Moyo Hilir, Kabupaten Sumbawa. Masjid Samsul Hidayah diresmikan pada tanggal 14 Safar 1435 Hijriyah tepatnya pada tanggal 15 januari 2014. Walaupun Masjid Samsul Hidayah terbilang baru, tetapi dalam masalah keuangannya pengurus masjid selalu mengumumkan setiap orang yang menyumbangkan dana di masjid tanpak menyebutkan nama penyumbang. Selain diumumkan, pemasukan dan pengeluaran kas dipublikasikan dengan cara menempelkan semua pengeluaran dan pemasukan kas di majalah dinding Masjid Samsul Hidayah.

Masjid Samsul Hidayah merupakan masjid terbesar di Desa Moyo. Salah satu sumber utama pendapatan masjid yaitu berasal dari kotak amal, infaq, sadaqah dari para jamaah masjid dan masyarakat sekitar, serta donator tetap dari Arab Saudi melalui angan kedua yaitu Ustad Munajad dari Pesantren Abu Bakar. Karena pendapatan masjid bersumber dari masyarakat dan para donator, maka pengurus masjid harus mempertanggungjawabkan seluruh kegiatan yang diadakan terutama dalam hal pengelolaan keuangan masjid mengingat besarnya pendapatan masjid setiap bulan dan setiap masa panen. Sehingga harus dilakukannya pencatatan serta laporan keuangan yang baik dan sesuai dengan standar pelaporan keuangan yang berlaku yaitu Pernyataan Standar Akuntansi Keuangan Nomor 45 (PSAK No. 45).

Melihat dari permasalahan yang ada di Masjid Samsul Hidayah desa Moyo, peneliti memandang bahwa Pernyataan Standar Akuntansi Keuangan (PSAK No. 45) merupakan hal yang sangat penting untuk diterapkan dalam organisasi nirlaba (masjid) agar kesesuaian antara laporan keuangan organisasi nirlaba (masjid) dengan standar yang berlaku yaitu Pernyataan Standar Akuntansi Keuangan (PSAK No. 45).

\section{METODE PENELITIAN}

\section{A. Jenis Penelitian}

Dalam penelitian ini, jenis penelitian yang digunakan adalah penelitian kualitatif dengan pendeketan interpretif. Menurut Moleong (2018) penelitian kualitatif merupakan penelitian yang bermaksud untuk memahami fenomena tentang apa yang dialami oleh subjek penelitian misalnya perilaku, persepsi, motivasi, tindakan dan lainlain secara holistik dan cara deskriptif dalam bentuk kata-kata dan bahasa, pada suatu konteks khusus yang alamiah dan memanfaatkan berbagai metode alamiah. Burrell dan Morgan (1979) menggambarkan sifat interpretif sebagai paradigma yang memiliki karakteristik untuk memahami dan menjelaskan dunia sosial yang tidak terlepas dari kacamata personal yang terlibat langsung dalam sebuah proses sosial. Pada penelitian ini peneliti langsung mengobservasi, mengidentifikasikan, serta mendeskripsikan atau memberi gambaran tentang laporan keuangan menurut PSAK No. 45, kemudian informasi tersebut digunakana untuk membuat laporan keuangan organisasi Masjid Al-Iman Bukit Tinggi, yang bertempat di Jalan Ki hajar Dewantara, Kelurahan Pekat, Kecamatan Sumbawa. Penelitian ini dimulai dari bulan September 2019 sampai bulan Januari 2020. Menurut Sugiyono (2010), analisis data merupakan proses mencari dan menyusun data yang diperoleh dari hasil wawancara, catatan lapangan, ataupun bahan-bahan lainnya yang secara sistematis, mudah dipahami, dan temuannya dapat diinformasikan kepada orang lain. Adapun tahap-tahap analisis data dalam penelitian ini adalah:

1. Pengumpulan data serta informasi profil masjid dan laporan keuangan Masjid Al-Iman Bukit Tinggi. 
2. Penyajian data dalam bentuk uraian singkat berupa analisis laporan keuangan Masjid Al-Iman Bukit Tinggi.

3. Menganalisis data serta informasi mengenai kesesuaian laporan keuangan Masjid Samsul Hidayah Desa Moyo dengan PSAK No. 45.

4. Menarik kesimpulan dari data dan informasi yang telah di analisis untuk kemudian dapat memberikan saran serta masukan demi keberlangsungan organisasi Masjid Al-Iman Bukit Tinggi.

\section{HASIL DAN PEMBAHASAN}

\section{A. Laporan Keuangan Masjid Al-Iman Bukit} Tinggi

Berdasarkan Pernyataan Standar Akuntansi Keuangan (PSAK No.45)

1. Laporan Posisi Keuangan

Menyediakan informasi mengenai aktiva, kewajiban dan aktiva bersih serta informasi mengenai hubungan diantara unsur-unsur tersebut pada waktu tertentu. Berikut laporan posisi keuangan Masjid Samsul Hidayah Desa Moyo berdasarkan PSAK No. 45 dilihat pada tabel 1.

Tabel 1

Laporan posisi keuangan

\begin{tabular}{|c|c|}
\hline $\begin{array}{r}\text { Masj } \\
\text { Untuk Tahun B }\end{array}$ & \\
\hline \multicolumn{2}{|l|}{ ASET } \\
\hline \multicolumn{2}{|l|}{ Aset Lancar } \\
\hline Kas dan Setara Kas & 88.995 .000 \\
\hline \multicolumn{2}{|l|}{ Aset Tidak Lancar } \\
\hline \multicolumn{2}{|l|}{ Aset Tetap } \\
\hline Tanah & 80.000 .000 \\
\hline Bangunan & 1.000 .000 .000 \\
\hline Mesin genset & 6.400 .000 \\
\hline Peralatan & 1.250 .000 \\
\hline Jumlah Aset Tetap & 1.087 .650 .000 \\
\hline Jumlah Aset & 1.176 .645 .000 \\
\hline \multicolumn{2}{|c|}{ KEWAJIBAN DAN ASET NETO } \\
\hline \multicolumn{2}{|c|}{ Kewajiban } \\
\hline Aset Tidak Terikat & 88.995 .000 \\
\hline Aset Terikat Temporer & 7.650 .000 \\
\hline Aset Terikat Permanen & 1.080 .000 .000 \\
\hline Jumlah Aset Neto & 1.176 .645 .000 \\
\hline
\end{tabular}

2. Laporan Aktivitas

Laporan aktivitas bertujuan untukmenyediakan informasi mengenai pengaruh transaksi dari peristiwa lain yang mengunah jumlah dan sifat aset neto, hubungan antara transaksi dan peristiwa lainnya dan bagaimana penggunaan sumber daya dalam pelaksanaan berbagai program atau jasa. Berikut laporan aktivitas Masjid Al-Iman Bukit Tinggi berdasarkan PSAK No. 45 dilihat pada tabel 2 .

$$
\text { Tabel } 3
$$

Laporan Arus Kas

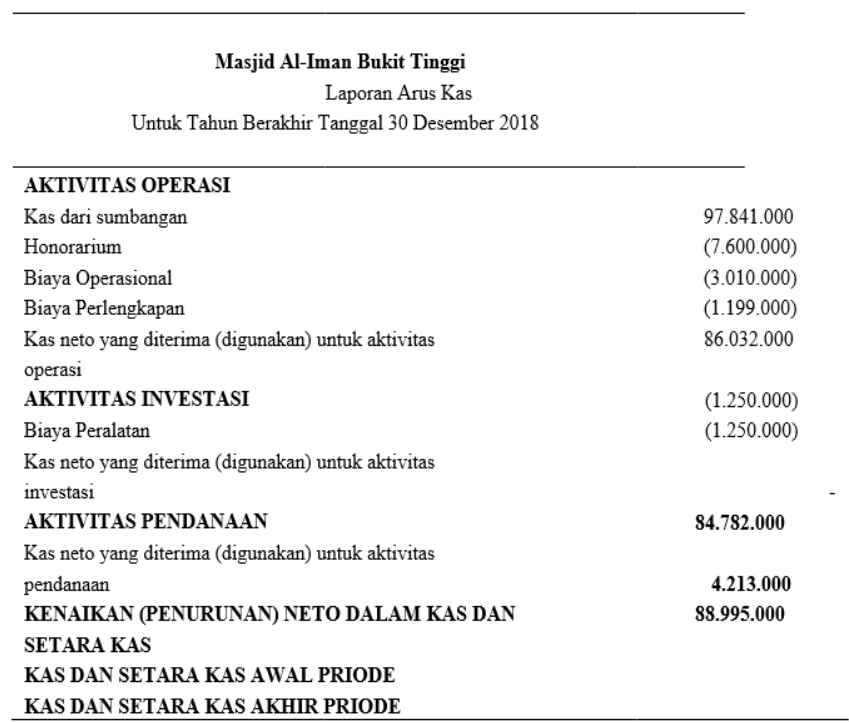

\section{Laporan Arus Kas}

Laporan arus kas bertujuan untuk menyajikan informasi mengenai penerimaan dan pengeluaran kas dalam suatu priode. Berikut laporan arus kas Masjid Samsul Hidayah Desa Moyo berdasarkan PSAK No.45 pada tabel 3. 


\begin{tabular}{c} 
Tabel 2 \\
Laporan Aktivitas \\
\hline Masjid Al-Iman Bukit Tinggi \\
Laporan Aktivitas \\
Untuk Tahun Berakhir Tanggal 30 Desember 2018 \\
\hline
\end{tabular}

PERUBAHAN ASET NETO TIDAK TERIKAT

Pendapatan
Sumbangan RT

Kotak Amal dan Dasawism

Kotak Amal Jum'at

Sumbangan Masyarakat

Jumlah

Beb

Biaya Kesejahteraan Marbot

Honorarium

Biaya Penceramah Kegiatan Keagamaan

Biaya Listrik, Air, Dan Telepon

Biaya Pemeliharaan \& Perbaikan Peralatar

BBM

Biaya Konsumsi dan Qori'ah Maulid

Biaya Pembuatan Spanduk Maulid

Pan Perlengkapan

Bampu

Biaya Pembelin 2 Unit Sapu Untuk Naep

Bay

Biaya Pembelian 2 Unit Bak Sampat

Kenaikan (Penurunan) Aset Neto Tidak Terikat

PERUBAHAN ASET NETO TERIKAT TEMPORE

PERUBAHAN ASET NETO TERIKAT PERMANEN

KENAIKAN ASET NETO

ASET NETO AWAL PRIODE

ASET NETO AKHIR PRIOD

\subsection{3 .000}

13.635 .000

5.623 .000
10.161 .000

10.161 .000

21.779 .000

4.000 .000

3.000 .000

600.000

1.215 .000

1.180 .000

215.000

300.000
100.000

142.000

65.000

270.000
270.000

330.000

330.000
122.000

11.809 .000

86.032 .000

7.650 .000

1.080 .000 .000

173.682 .000

2.963 .000
6.645 .000

\section{PENUTUP}

\section{A. Kesimpulan}

Berdasarkan hasil analsis data dapat disimpulkan bahwa laporan keuangan Masjid Al-Iman Bukit Tinggi belum sesuai dengan standar yang berlaku yaitu Pernyataan Standar Akuntansi Keuangan (PSAK No. 45) karena tidak memenuhi ketentuan yang terdapat dalam PSAK No 45.

1. Masjid Al-Iman Bukit Tinggi tidak menyajikan laporan posisi keuangan.

2. Masjid Al-Iman Bukit Tinggi tidak menyajikan laporan aktivitas.

3. Masjid Al-Iman Bukit Tinggi tidak menyajikan laporan arus kas.

B. Saran

Dari kesimpulan hasil penelitian, terdapat saran yang dapat dipertimbangkan oleh pengurus Masjid Al-Iman Bukit Tinggi. saran yang dapat dijadikan bahan pertimbangan dan masukan dalam penyusunan laporan keuangan Masjid Al-Iman Bukit Tinggi yaitu sebagai berikut:

1. Peneliti menyarankan kepada bendahara Masjid Al-Iman Bukit Tinggi lebih teliti lagi dalam perhitungan laporan keuangan masjid

2. Peneliti menyarankan kepada Masjid Al-Iman Bukit Tinggi agar menyusun laporan keuangan sesuai dengan Pernyataan Standar Keuangan (PSAK No. 45).
C. Implikasi Penelitian

1. Praktis

Sebagai bahan acuan pihak Masjid AlIman Bukit Tinggi dalam membuat laporan keuangan organisasi berdasarkan Pernyataan Standar Akuntansi Keuangan (PSAK) Nomor 45.

2. Teoritis

Hasil penelitian ini dapat dijadikan bahan referensi pengembangan untuk penelitian selanjutnya.

\section{DAFTAR PUSTAKA}

Darmayasa, I.N., dan Y, Riska Aneswari. 2015. Paradigma Interpretif Pada Penelitian Akuntansi Indonesia. Jurnal Akuntansi Multiparadigma. Vol. 6(3)

Ikatan Akuntansi Indonesia (IAI). 2011. Organisasi Nirlaba. Pernyataan Standar Akuntansi Keuangan (PSAK) No. 45 Revisi 2011, Jakarta.

Ikatan Akuntansi Indonesia (IAI). 2011. Pernyataan Standar Akuntansi Keuangan No. 45 (Revisi 2011) Pelaporan Keuangan Entitas Nirlaba, Jakarta.

Ikatan Akuntansi Indonesia. 2012. Karakteristik Organisasi Nirlaba. PSAK No. 45, No. 109. Ikatan Akuntansi Indonesia, Jakarta.

Jusup, A.H. 2005. Dasar-dasar Akuntansi. Jilid 1. Sekolah Tinggi Ilmu Ekonomi YKPN, Yogyakarta. Jianti,

Ervianti . 2017. Penerapan Akuntansi Pokok Organisasi Nirlaba Pada Masjid AlJihad Banjarmasin.

Moleong, L.J. 2008. Metodologi Penelitian Kualitatif: Edisi Revisi. PT. Remaja Rosdakarya, Bandung.

Moleong, L.J. 2010. Metodologi Penelitian Kualitatif. PT. Remaja Rosdakarya, Bandung.

Nareimawati, U. 2008. Metodologi Penelitian Kualitatif Dan Kuantitatif: Teori Dan Aplikasi.

Sugiyono. 2010. Metode penelitian kuantitatif, kualitatif, dan R \& D. Alfabeta Bandung. 